\title{
Management of idiopathic pediatric syringohydromyelia
}

\author{
Analiz Rodriguez, MD, PhD, ${ }^{1}$ Elizabeth N. Kuhn, MD, ${ }^{2}$ Aravind Somasundaram, BS, ${ }^{1}$ and \\ Daniel E. Couture, MD1
}

\begin{abstract}
${ }^{1}$ Department of Neurosurgery, Wake Forest Baptist Medical Center, Winston-Salem, North Carolina; and 2Department of Neurosurgery, University of Alabama at Birmingham Hospital, Birmingham, Alabama
\end{abstract}

\begin{abstract}
OBJECT Syringohydromyelia is frequently identified on spinal imaging. The literature provides little guidance to decision making regarding the need for follow-up or treatment. The purpose of this study was to review the authors' experience in managing pediatric syringohydromyelia of unknown cause.

METHODS A single-institution retrospective review of all cases involving pediatric patients who underwent spinal MRI from 2002 to 2012 was conducted. Patients with idiopathic syringohydromyelia (IS) were identified and categorized into 2 subgroups: uncomplicated idiopathic syrinx and IS associated with scoliosis. Clinical and radiological course were analyzed.
\end{abstract}

RESULTS Ninety-eight patients (50 female, 48 male) met the inclusion criteria. Median age at diagnosis of syrinx was 11.9 years. Median maximum syrinx size was $2 \mathrm{~mm}$ (range $0.5-17 \mathrm{~mm}$ ) and spanned 5 vertebral levels (range 1-20 vertebral levels). Thirty-seven patients had scoliosis. The most common presenting complaint was back pain (26\%). Clinical follow-up was available for 78 patients (80\%), with a median follow-up of 20.5 months (range 1-143 months). A neurological deficit existed at presentation in $36 \%$ of the patients; this was either stable or improved at last follow-up in 64\% of cases. Radiological follow-up was available for 38 patients (39\%), with a median duration of 13 months (range 2-83 months). There was no change in syrinx size in $76 \%$ of patients, while $16 \%$ had a decrease and $8 \%$ had an increase in syrinx size. Thirty-six patients had both clinical and radiological follow-up. There was concordance between clinical and radiological course in 14 patients (39\%), with 11 patients (31\%) showing no change and 3 patients (8\%) showing clinical and radiological improvement.

No patients had concurrent deterioration in clinical and radiological course. One patient with scoliosis and muscular dystrophy underwent direct surgical treatment of the syrinx and subsequently had a deteriorated clinical course and decreased syrinx size.

CONCLUSIONS There remains a paucity of data regarding the management of pediatric IS. IS in association with scoliosis can complicate neurosurgical decision making. There was no concordance between radiological syrinx size increase and clinical deterioration in this cohort, indicating that surgical decision making should reflect clinical course as opposed to radiological course.

http://thejns.org/doi/abs/10.3171/2015.3.PEDS14433

KEY WORDS idiopathic syrinx; syringohydromyelia; pediatric neurosurgery; syringomyelia; congenital

$\mathrm{S}$ YRINGOHYDROMYELIA is a term that refers to cystic dilatations of the parenchyma or central canal of the spinal cord. There is an association of syringomyelia with many neurodevelopmental diseases such as Chiari Type I malformation, tethered cord syndrome, myelomeningocele, diastematomyelia, and spinal lipomas. Patients with spinal cord trauma or arachnoiditis can also develop syringohydromyelia. ${ }^{17}$

Idiopathic syringohydromyelia (IS) is generally accepted to be syringohydromyelia that is not associated with any of the previously mentioned identifiable causes or underlying conditions. IS can pose a treatment conundrum as the natural history is poorly understood. Most neurosurgeons intervene if the patient is symptomatic or if the lesion increases in size. The few studies that have been published on this topic have suggested that this is a benign condition that generally can be managed conservatively with observation. The length of the observation period remains quite variable and can be from several months to years. ${ }^{7,10}$ The presence of syringohydromyelia and concomitant scolio-

\section{ABBREVIATION IS = idiopathic syringohydromyelia}

SUBMITTED August 16, 2014. ACCEPTED March 23, 2015.

INCLUDE WHEN CITING Published online July 24, 2015; DOI: 10.3171/2015.3.PEDS14433.

DISCLOSURE The authors report no conflict of interest concerning the materials or methods used in this study or the findings specified in this paper. 
sis in some patients can further complicate the clinician's decision-making process. In this paper, we describe our experience with IS in the pediatric population, incorporating both clinical and radiological data. To our knowledge, this is the largest single-institution report on IS in the pediatric population.

\section{Methods}

\section{Patient Population and Follow-Up}

A single-institution retrospective review was conducted of all cases involving pediatric patients (age $\leq 18$ years) with syringohydromyelia on spinal MRI from 2002 to 2012 at Wake Forest Baptist Health following institutional review board approval. Searching MRI radiology reports for the terms "syrinx," "syringomyelia," "hydromyelia," "syringohydromyelia," and "enlarged central canal" using Primordial software (Primordial Inc.) initially identified 1967 patients. This software is directly linked to our institution's picture archiving and communication system. Inclusion criteria were age $<18$ years at the time of MRI and measurable cystic dilation of the spinal cord (diameter of $0.5 \mathrm{~mm}$ or greater on axial T2-weighted imaging spanning at least the length of a vertebral body) on MRI. Cystic dilation of the central canal of the conus was considered a terminal ventricle and excluded. After removing duplicate patients and records that had no syrinx, 275 patients met the inclusion criteria. Patients with Chiari Type I or II malformation, a tumor in the central nervous system, encephalocele or other congenital brain malformation, neurovascular disorder, infection, traumatic spinal cord injury, traumatic brain injury, tethered cord syndrome (including lipoma and fatty filum), or spina bifida spectrum (including meningocele, myelomeningocele, and lipomyelomeningocele) were excluded. This left 98 patients who met all criteria for inclusion.

Clinical data recorded included age, sex, symptoms and physical examination findings at presentation, comorbidities, type of treatment, and symptoms and physical examination findings from the most recent clinical follow-up. Radiological data recorded included follow-up time, maximum syrinx diameter, vertebral levels the syrinx spanned, and the change in syrinx size on subsequent MRI.

\section{Statistics}

Chi-square test was used to compare clinical course, and Fisher exact test was used to compare radiological course between idiopathic syrinx and scoliosis.

\section{Results}

The study population consisted of 50 female patients (51\%) and 48 male patients. The median age at initial MRI diagnosis was 11.9 years (range 10 days-18.4 years). Median clinical follow-up was 20.5 months, and median radiological follow-up was 13 months. The median maximum syrinx diameter was $2 \mathrm{~mm}$ (range $0.5-17 \mathrm{~mm}$ ) and the median number of vertebral levels spanned was 5 (range 1-20). Eighty-one of the patients had a syrinx diameter equal to or greater than $2 \mathrm{~mm}$. Forty-three patients had a syrinx diameter of $2 \mathrm{~mm}$. The distribution of syrinx locations was thoracic $(n=43)$; cervicothoracic $(n=18)$; cervical $(\mathrm{n}=15)$; cervicothoracolumbar $(\mathrm{n}=12)$; thoracolumbar $(\mathrm{n}=10)$. Table 1 summarizes the cohort's basic demographics. Sixty-one patients had uncomplicated IS and 37 patients had scoliosis.

\section{Clinical Course}

Clinical follow-up was available for 78 patients $(80 \%)$ of the entire cohort, with a median follow-up duration of 20.5 months (range 1-143 months). The reason for presentation and presenting neurological deficit are shown in Table 2. Eighty-three $(85 \%)$ of 98 patients had a presenting complaint, while in the remaining $15 \%$ of patients, a syrinx was incidentally found. The reasons for incidental discovery of a syrinx were as follows: delayed walking (7), sacral dimple (3), syrinx incidentally noticed on nonspinal imaging (3), and abnormal skin marking on back (2). The top 5 most common presenting complaints of the cohort were back pain $(\mathrm{n}=22 ; 22 \%)$, gait or balance disturbance $(\mathrm{n}=14 ; 14 \%)$, extremity pain $(\mathrm{n}=12 ; 12 \%)$, scoliosis $(\mathrm{n}=$ $8 ; 8 \%)$, and headache $(\mathrm{n}=8 ; 8 \%)$. At presentation, $36 \%$ of patients had a neurological deficit on examination. Neurological deficits included gait or balance disturbance $(\mathrm{n}=$ $11 ; 11 \%)$, focal weakness $(n=8 ; 8 \%)$, hyperreflexia $(n=6$; $6 \%)$, hyporeflexia $(n=4 ; 4 \%)$, bowel or bladder dysfunction $(n=3 ; 3 \%)$, and sensory deficit $(n=3 ; 3 \%)$.

Twenty-two patients (22\%) with clinical follow-up were asymptomatic and without any objective physical examination findings at presentation; all of these patients remained asymptomatic during the follow-up period. Twelve patients (12\%) had a stable clinical course, 38 patients (39\%) improved, and the clinical course of 6 patients (6\%) deteriorated. Thirty of these patients (31\%) had complete resolution of their initial symptoms while the other 8 patients (8\%) had partial improvement in their symptoms.

One patient with scoliosis underwent surgical treatment of a syrinx via placement of a syringopleural shunt. This patient presented at 10 years of age with hyporeflexia and Ullrich muscular dystrophy and had a syrinx that spanned 3 vertebral levels, with a maximum diameter of $5 \mathrm{~mm}$ diagnosed at 13 years. The syringopleural shunt was placed the year following syrinx diagnosis in an effort to improve declining neurological status, namely, bilateral lower extremity weakness. The patient eventually became nonambulatory and required a subsequent spinal deformity correction to attempt to improve restrictive lung disease. MRI performed 6 months after the initial surgery demonstrated that the syrinx diameter was reduced to $40 \%$ of its original size (Fig. 1); however, the patient's clinical condition continued to deteriorate with the development of further respiratory dysfunction and bilateral lower extremity weakness, likely related to muscular dystrophy.

\section{Radiological Course}

Radiological follow-up was available for 38 patients (39\%), with a median follow-up duration of 13 months (range 2-83 months). Syrinx size was stable in 29 patients (76\%). Seventeen patients had a syrinx diameter less than 2 $\mathrm{mm}$ (Table 3). Three syringes (8\%) increased in size, with 1 increasing in both length and diameter $(67 \%$ increase in length, $50 \%$ increase in diameter) and 2 increasing in diameter alone (10\% and 67\% increases). Six syringes (16\%) decreased in size, with 2 disappearing completely and 4 
TABLE 1. Clinical and demographic characteristics

\begin{tabular}{lccc}
\hline \multicolumn{1}{c}{ Characteristic } & Total Cohort $(\mathrm{n}=98)$ & IS $(\mathrm{n}=61)$ & Scoliosis $(\mathrm{n}=37)$ \\
\hline Age at diagnosis, median yrs (range) & $11.9(0.03-18.4)$ & $9.07(0.3-18.4)$ & $13.8(0.9-17.6)$ \\
\hline M/F, $n$ & $48 / 50$ & $33 / 28$ & $16 / 21$ \\
\hline Syrinx location, $n$ & & & 5 \\
Cervical & 15 & 10 & 4 \\
Cervicothoracic & 18 & 14 & 26 \\
Thoracic & 43 & 17 & 0 \\
Thoracolumbar & 10 & 10 & 2 \\
Cervicothoracolumbar & 12 & 10 & $28(1-143)$ \\
Follow-up, median months (range) & & $12(9-92)$ & $18(2-83)$ \\
Clinical & $20.5(1-143)$ & $13(6-82)$ & \\
Radiological & $13(2-83)$ & & \\
\hline
\end{tabular}

decreasing in diameter alone $(25 \%, 40 \%, 50 \%$, and $60 \%$ of original diameter) (Table 3 ).

Thirty-six patients had both clinical and radiological follow-up. There was concordance between clinical and radiological course in 14 patients (39\%), with 11 patients (31\%) showing no change and 3 patients (8\%) showing clinical and radiological improvement. Figure 2 shows an MR image obtained in a patient who presented with headaches at 3 years of age and was found to have a cervical syrinx without Chiari malformation. The patient had no neurological deficit and headaches improved over time while syrinx imaging remained stable over a span of 4 years. No patients had concurrent deterioration in clinical and radiological course. Fourteen patients (39\%) had clinical improvement without radiological change, while 2 patients $(6 \%)$ had clinical improvement with radiological deterioration. Figure 3 demonstrates diameter enlargement of a throracolumbar syrinx in a 14-year-old male who had

\section{TABLE 2. Presenting complaints*}

\begin{tabular}{lrcc}
\hline \multicolumn{1}{c}{ Sign or Symptom } & $\begin{array}{c}\text { Total } \\
\text { Cohort } \\
(\mathrm{n}=98)\end{array}$ & $\begin{array}{c}\text { IS } \\
(\mathrm{n}=61)\end{array}$ & $\begin{array}{c}\text { Scoliosis } \\
(\mathrm{n}=37)\end{array}$ \\
\hline Complaint & & & \\
$\quad$ Back pain & 22 & 13 & 9 \\
Gait or balance disturbance & 14 & 12 & 2 \\
Extremity pain & 12 & 7 & 5 \\
Scoliosis & 8 & 0 & 8 \\
Headache & 8 & 6 & 2 \\
Neck pain & 7 & 5 & 2 \\
Bowel or bladder dysfunction & 5 & 4 & 1 \\
Weakness & 2 & 2 & 0 \\
Trauma & 2 & 2 & 0 \\
Other & 3 & 3 & 0 \\
None & 15 & 7 & 8 \\
\hline Neurological deficit & & & \\
Gait or balance disturbance & 11 & 11 & 0 \\
Focal weakness & 8 & 5 & 3 \\
Hyperreflexia & 6 & 3 & 3 \\
Hyporeflexia & 4 & 3 & 1 \\
Bowel/bladder dysfunction & 4 & 4 & 0 \\
Sensory deficit & 3 & 3 & 0 \\
None & 63 & 33 & 30 \\
\hline Valus & & &
\end{tabular}

\footnotetext{
${ }^{*}$ Values are numbers of patients.
}

transient quadriparesis following a trauma. The patient did not have neurological deficit at last follow-up (1.5 years after the event) despite the enlargement of the syrinx. Two patients $(6 \%)$ had clinical deterioration without radiological change, and 1 patient $(3 \%)$ had clinical deterioration with radiological improvement. Two patients $(6 \%)$ had radiological improvement without clinical change, and 1 patient (3\%) had radiological deterioration without clinical change.

\section{Uncomplicated Idiopathic Syrinx}

Sixty-one patients had true idiopathic syrinx; their syringes spanned a median of 5 vertebral levels (range

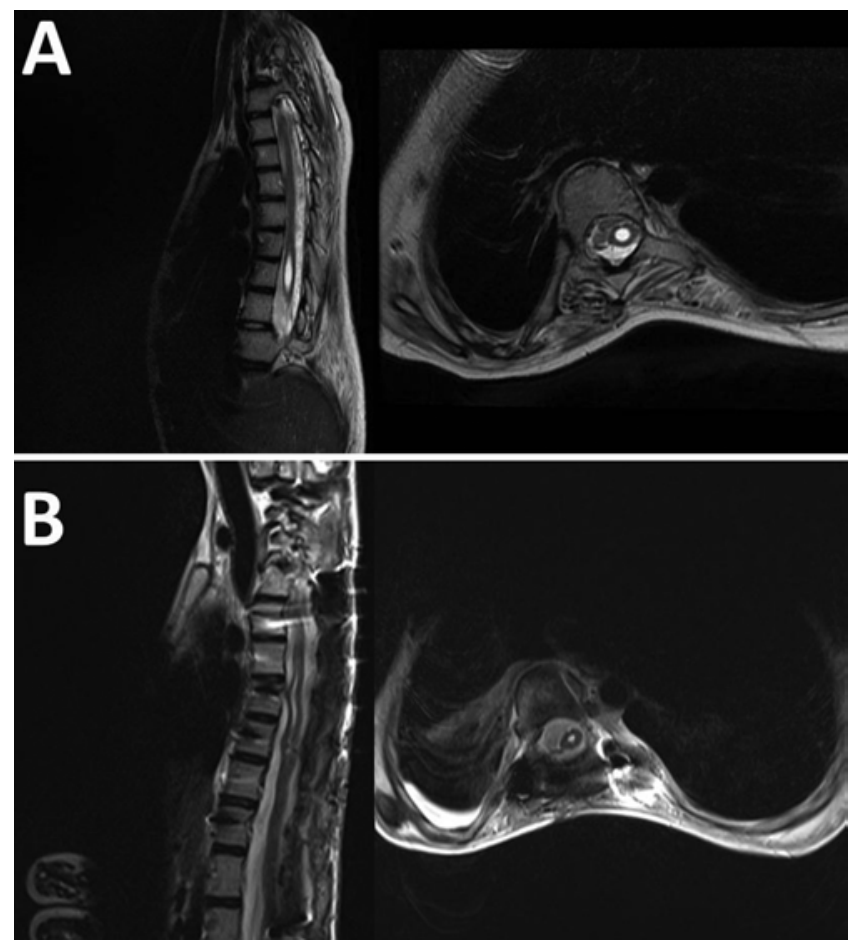

FIG. 1. Images obtained in a patient with IS associated with scoliosis who underwent direct surgical intervention of a syrinx as well as spinal deformity correction. A: Sagittal (left) and axial (right) T2-weighted preoperative MR images showing a thoracic syrinx. B: Sagittal (left) and axial (right) T2-weighted MR images demonstrating subsequent postsurgical decrease in syrinx diameter to $40 \%$ of its original size. 
TABLE 3. Comparison of syrinx course by cause

\begin{tabular}{lcc}
\hline \multicolumn{1}{c}{ Characteristic } & $\begin{array}{c}\text { Idiopathic } \\
(\mathrm{n}=61)\end{array}$ & $\begin{array}{c}\text { Scoliosis } \\
(\mathrm{n}=37)\end{array}$ \\
\hline $\begin{array}{l}\text { Median length, no. of vertebral levels } \\
\text { spanned (range) }\end{array}$ & $5(1-18)$ & $5(1-20)$ \\
\hline $\begin{array}{l}\text { Median diameter, mm (range) } \\
\text { Pts w/ <2 mm diameter, } \mathrm{n}\end{array}$ & $2(0.5-17)$ & $2(1-11)$ \\
\hline Median follow-up period, months & 8 & 9 \\
\hline Clinical & 12 & 28 \\
\hline Radiological & 13 & 17.5 \\
\hline Clinical course, $\mathrm{n}(\%)$ & & \\
\hline Follow-up available & $45(74)$ & $33(89)$ \\
\hline Asymptomatic & $9(20)$ & $13(39)$ \\
\hline Stable & $9(20)$ & $3(9)$ \\
\hline Improved & $24(53)$ & $14(42)$ \\
\hline Deteriorated & $3(7)$ & $3(9)$ \\
\hline Radiological course, $\mathrm{n}(\%)$ & & $14(38)$ \\
\hline Follow-up available & $24(39)$ & $10(71)$ \\
\hline Stable & $19(79)$ & $4(29)$ \\
\hline Smaller & $2(8)$ & 0 \\
\hline Larger & $3(13)$ & \\
\hline
\end{tabular}

Pts = patients.

1-18 vertebral levels) and had a median diameter of 2 $\mathrm{mm}$ (range $0.5-17 \mathrm{~mm}$ ). Forty-five patients $(73.8 \%$ ) had clinical follow-up, with a median duration of 12 months. Twenty-four patients (39.3\%) had radiological follow-up, with a median duration of 13 months.

Syrinx size was stable in 19 patients (79.2\%). Two syringes $(8.3 \%)$ decreased in size, with both decreasing in diameter alone $(25 \%$ and $50 \%$ of original size). Three syringes $(12.5 \%)$ increased in size, with 1 increasing in both diameter and length $(67 \%$ increase in length, $50 \%$ increase in diameter), and 2 increasing in diameter alone (10\% and $17 \%$ increases). None of the patients whose syringes increased in size experienced associated clinical deterioration.

Nine patients (20\%) were asymptomatic and without any objective physical examination findings at presentation, and all of these patients remained asymptomatic during the follow-up period. Nine patients $(20 \%)$ had a stable clinical course, 24 patients $(53.3 \%)$ improved, and 3 patients $(6.7 \%)$ deteriorated. Nineteen patients $(42 \%)$ had complete resolution of their initial symptoms, while 5 patients $(11.1 \%)$ had partial improvement in their symptoms.

\section{Scoliosis}

Thirty-seven patients had scoliosis; their associated syringes spanned a median of 5 vertebral levels (range 1-20 vertebral levels) and had a median diameter of 2 $\mathrm{mm}$ (range 1-11 $\mathrm{mm}$ ). Of the patients with scoliosis, the cause was idiopathic in 30 patients $(81 \%)$, congenital in 5 patients $(13 \%)$, and neuromuscular in 4 patients $(11 \%$; cerebral palsy, trisomy 9p, Ullrich muscular dystrophy, myotonic muscular dystrophy). Thirty-three patients (89\%) had clinical follow-up with a median duration of 28 months. Fourteen patients $(38 \%)$ had radiological follow-up, with
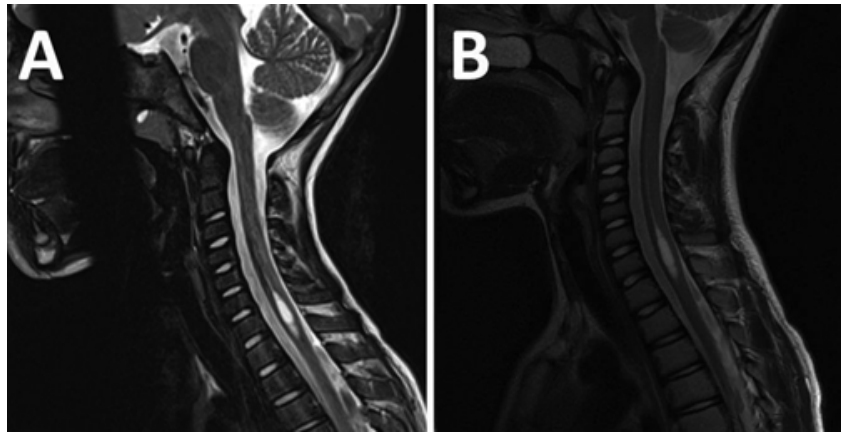

FIG. 2. Sagittal T2-weighted MR images obtained in a patient who presented with headaches at 3 years of age, showing a cervical syrinx (A) that was stable at last follow-up (B).

a median duration of 18 months. Seventeen patients (46\%) had surgical correction of their scoliosis. Syrinx size was stable in 10 patients (71\%). Four syringes (29\%) decreased in size, with 2 disappearing completely, and 2 decreasing in diameter alone ( $40 \%$ and $60 \%$ of original size). No syrinx increased in size.

Thirteen patients $(33.3 \%)$ were asymptomatic and without any objective physical examination findings at presentation; all of these patients remained asymptomatic during the follow-up period. Three patients $(14.3 \%)$ had a stable clinical course, 14 patients (39.5\%) improved, and 3 patients $(7.1 \%)$ deteriorated (Table 3 ).

Table 3 compares syrinx course for patients with true idiopathic syrinx and scoliosis. There was no statistically significant difference in radiological course $(p=0.128)$ or clinical course $(\mathrm{p}=0.201)$ between patients with idiopathic syrinx or scoliosis.

\section{Discussion}

A syrinx is usually defined as a fluid-filled cavity with a gliotic lining within the spinal cord. Hydromyelia is a term that refers to a fluid-filled cavity within the spinal cord lined by ependyma. Hydromyelia is a centralized slit-like cavitation within the spinal canal, which likely results from a developmentally nonobliterated central canal. These patients may present with pain but do not have neurological deficits or abnormalities on electrophysiological monitoring. ${ }^{14}$ The 2 terms are often interchanged. To differentiate syringomyelia from hydromyelia, a syrinx is often defined as being greater than $1 \mathrm{~mm}$ in diameter and extending over at least 2 vertebral body levels in length. In our study, we included all patients with evidence of spinal cord cavitation as we were also interested in assessing the management of syringohydromyelia. Regardless of the size of cystic dilation, these patients are often still referred to neurosurgeons for evaluation. Therefore, when referring to the presence of a "syrinx" in our cohort, we refer to any cystic dilatations within the spinal canal. The majority of our patients $(84 \%)$ had cystic dilations that were equal to or greater than $2 \mathrm{~mm}$. In the 17 patients with less than 2 $\mathrm{mm}$ of cystic dilation, the findings may represent normal variants. Of these patients, $61 \%$ had symptoms or neurological deficit at presentation, but it is unlikely that these spinal cord variants are causative of the patients' presentation. However, we choose to include patients with a syrinx 


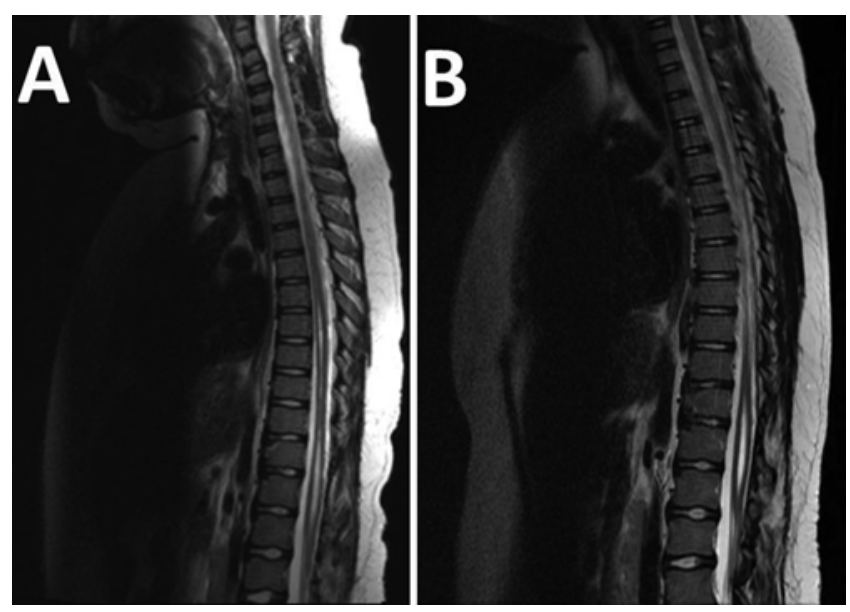

FIG. 3. Sagittal T2-weighted MR images obtained in a 14-year-old male who had transient quadriparesis following a trauma, showing a thoracolumbar syrinx (A) that was increased at last follow-up (B).

diameter of less than or equal to $2 \mathrm{~mm}$ as they represent treatment dilemmas for many clinicians.

The etiology of syringohydromyelia remains unknown. Historically, the pathophysiological theories of the etiology of syringohydromyelia have evolved. Initially, the strong association of syringes with neurodevelopmental anomalies, such as craniocervical junction diseases, led many clinicians to believe that these abnormalities were causative. In patients without these presumed causative pathologies, it was believed that an inciting traumatic or infectious event caused alterations in CSF dynamics. ${ }^{9}$ Williams theorized that CSF flow obstructions led to pressure dissociations in which CSF passes through the obstructions during episodes of increased intracranial pressure and, via a ball-valve mechanism, is not able to egress back out even after the pressure has normalized.,11,18 This theory was the first to explain etiology, regardless of the presumed underlying pathology, and was the basis for multiple modern theories. ${ }^{5,6}$

There remains a paucity of studies on the etiology and natural history of pediatric IS. Therefore, treatment among physicians can be quite variable. In contrast, there is a clear consensus among pediatric neurosurgeons that syringomyelia associated with Chiari Type I malformation warrants neurosurgical intervention with posterior fossa decompression..$^{13}$

In our study, we retrospectively reviewed the cases of 98 patients who had radiological evidence of syringohydromyelia over a 10 -year period at our institution. These patients were divided into 2 main groups, namely, uncomplicated IS and syringohydromyelia associated with scoliosis.

In our cohort, median age of diagnosis was 11.9 years, and median diameter and length of cystic dilatations were $2 \mathrm{~mm}$ and spanned over 5 vertebral levels, respectively. The majority of dilatations were within the thoracic region of the spinal cord. In comparison with other studies of pediatric idiopathic syringomyelia, we report a smaller median diameter; however, we applied a less strict definition of what constitutes "syrinx." As in other series, the thoracic region was the most common location for a syrinx.$^{7,10}$ In this study, the most common presenting complaint was back pain followed by gait or balance disturbance. In adults with symptomatic syringomyelia, patients often complain of sensory deficits and ambulatory difficulties. ${ }^{6}$ In pediatric series, back pain, gait difficulty, and continence issues are common presentations of syringomyelia, but also can be presenting symptoms of tethered cord syndrome. ${ }^{17}$ Therefore, many of these patients are referred for spinal imaging. However, in our cohort, 15 patients received neurosurgical referral for incidentally discovered imaging findings.

Gait disturbance and weakness were the most common presenting neurological deficits, though we found that fewer than half of patients presented with any neurological deficit. All patients who were asymptomatic at presentation remained so, and the clinical condition of only $8 \%$ of patients deteriorated. These results support the theory that pediatric IS is a benign entity. To ascertain whether other factors influenced outcomes, we compared IS subgroups.

Sixty-one patients had uncomplicated IS, and clinical follow-up was available for $45(74 \%)$ of these patients. Radiological follow-up was available for 24 patients. These variable follow-up times are reflective of the lack of any set protocol and, hence, the differing treatment paradigms used by clinicians. For many cases, it was determined that the patient did not warrant further follow-up. Of the patients with uncomplicated IS with clinical follow-up, only 3 patients experienced worsening symptoms. These patients did have radiological evaluation but there was no concordance between clinical decline and radiological progression of syringohydromyelia. In the subset of uncomplicated IS, 3 patients had an increase in syrinx size, with 1 patient having both an increase in diameter and length. However, none of the patients with radiological progression experienced deterioration of their clinical status, and none of them received surgical intervention.

We also included patients with scoliosis in this cohort. Scoliosis has been associated with syringomyelia and can be a sign of developing syringomyelia. ${ }^{1}$ Controversy exists on the best management of these patients. There are studies which indicate that treatment of the syrinx does not improve the scoliosis. ${ }^{2,12}$ Conversely, decompression of the syrinx may improve or stabilize the scoliosis. ${ }^{16,19}$ When syringomyelia and scoliosis are associated with Chiari Type I malformation, early decompression of the craniocervical junction results in improvement or stabilization of the scoliotic deformity in a few patients. ${ }^{3}$ There also is an association between increased syrinx size and presence of scoliosis in patients with Chiari Type I malformations. ${ }^{4}$

Thirty-seven IS patients had concomitant scoliosis, and $89 \%$ of these patients had clinical follow-up. The majority of patients had idiopathic scoliosis. Fourteen patients had radiological follow-up, and syrinx size was stable or decreased in all 14 patients; no patient had increase in syrinx size. Of the 4 patients whose syrinx size decreased, only 1 had surgery for deformity prior to the decrease in syrinx size. One patient had no surgery for his deformity, and the other 2 patients underwent surgery for their deformity after the decrease in syrinx size. One patient underwent syrinx decompression and showed decreased syrinx size but experienced clinical deterioration, which likely was secondary to muscular dystrophy. 
There was no statistically significant difference in radiological or clinical course among the 2 subgroups: uncomplicated IS and scoliosis-associated IS. We chose to use a broad definition of IS to have an accurate representation of pediatric patients referred to neurosurgeons for evaluation. Interestingly, there was no concordance between radiological syrinx size increase and clinical course deterioration. This phenomenon has been noted in previous studies of pediatric IS. ${ }^{7,10}$ One small study on the natural history of pediatric IS identified 1 patient who had an increase in syrinx size that correlated with a decline in clinical course; however, this patient had a Chiari Type I malformation..$^{15}$ Direct surgical management of the syrinx in 1 patient did not improve clinical course. The majority of patients remained stable or improved in their clinical course, indicating that pediatric IS is a benign entity.

Limitations of our study include its retrospective nature and small cohort. Also at our institution, the majority of pediatric patients with IS do not receive radiological follow-up; therefore, studying natural history is difficult. The median clinical follow-up in our study was close to 2 years. Our results are, therefore, only applicable to shortterm outcomes of these patients. Given that we reviewed cases spanning a 10-year period and included all patients with syringohydromyelia, to our knowledge, this study involved more patients $(n=38)$ with radiological follow-up than any previously published study. We chose to include all patients who were referred to a pediatric neurosurgeon. If clinicians do choose to follow these patients long term, serial MRI may not be indicated or cost-effective without neurological decline, even for patients with associated scoliosis. An increase in syrinx size alone without clinical decline should not be an impetus for surgical intervention in the short term. Further studies are needed to evaluate the need for continual long-term clinical assessment in pediatric IS patients.

\section{Conclusions}

There remain limited data regarding the natural history of pediatric IS. Pediatric IS can be further complicated by the presence of scoliosis. Our study indicates that direct surgical intervention of the syrinx is not indicated as the majority of these patients will be clinically stable or improved over time.

\section{References}

1. Bhangoo R, Sgouros S: Scoliosis in children with Chiari Irelated syringomyelia. Childs Nerv Syst 22:1154-1157, 2006

2. Bradley LJ, Ratahi ED, Crawford HA, Barnes MJ: The outcomes of scoliosis surgery in patients with syringomyelia. Spine (Phila Pa 1976) 32:2327-2333, 2007

3. Eule JM, Erickson MA, O'Brien MF, Handler M: Chiari I malformation associated with syringomyelia and scoliosis: a twenty-year review of surgical and nonsurgical treatment in a pediatric population. Spine (Phila Pa 1976) 27:1451-1455, 2002

4. Godzik J, Kelly MP, Radmanesh A, Kim D, Holekamp TF, Smyth MD, et al: Relationship of syrinx size and tonsillar descent to spinal deformity in Chiari malformation Type I with associated syringomyelia. J Neurosurg Pediatr 13:368-374, 2014

5. Greitz D: Unraveling the riddle of syringomyelia. Neurosurg Rev 29:251-264, 2006

6. Heiss JD, Snyder K, Peterson MM, Patronas NJ, Butman JA, Smith RK, et al: Pathophysiology of primary spinal syringomyelia. J Neurosurg Spine 17:367-380, 2012

7. Joseph RN, Batty R: Raghavan A, Sinha S, Griffiths PD, Connolly DJ: Management of isolated syringomyelia in the paediatric population-a review of imaging and follow-up in a single centre. Br J Neurosurg 27:683-686, 2013

8. Klekamp J: The pathophysiology of syringomyelia-historical overview and current concept. Acta Neurochir (Wien) 144:649-664, 2002

9. Koyanagi I, Iwasaki Y, Hida K, Houkin K: Clinical features and pathomechanisms of syringomyelia associated with spinal arachnoiditis. Surg Neurol 63:350-356, 2005

10. Magge SN, Smyth MD, Governale LS, Goumnerova L, Madsen J, Munro B, et al: Idiopathic syrinx in the pediatric population: a combined center experience. J Neurosurg Pediatr 7:30-36, 2011

11. Martin BA, Kalata W, Loth F, Royston TJ, Oshinski JN: Syringomyelia hydrodynamics: an in vitro study based on in vivo measurements. J Biomech Eng 127:1110-1120, 2005

12. Ozerdemoglu RA, Transfeldt EE, Denis F: Value of treating primary causes of syrinx in scoliosis associated with syringomyelia. Spine (Phila Pa 1976) 28:806-814, 2003

13. Rocque BG, George TM, Kestle J, Iskandar BJ: Treatment practices for Chiari malformation type I with syringomyelia: results of a survey of the American Society of Pediatric Neurosurgeons. J Neurosurg Pediatr 8:430-437, 2011

14. Roser F, Ebner FH, Sixt C, Hagen JMV, Tatagiba MS: Defining the line between hydromyelia and syringomyelia. A differentiation is possible based on electrophysiological and magnetic resonance imaging studies. Acta Neurochir (Wien) 152:213-219, 2010

15. Singhal A, Bowen-Roberts T, Steinbok P, Cochrane D, Byrne AT, Kerr JM: Natural history of untreated syringomyelia in pediatric patients. Neurosurg Focus 31(6):E13, 2011

16. Tomlinson RJ Jr, Wolfe MW, Nadall JM, Bennett JT, MacEwen GD: Syringomyelia and developmental scoliosis. J Pediatr Orthop 14:580-585, 1994

17. Tsitouras V, Sgouros S: Syringomyelia and tethered cord in children. Childs Nerv Syst 29:1625-1634, 2013

18. Williams B: The distending force in the production of "communicating syringomyelia." Lancet 2:189-193, 1969

19. Yeom JS, Lee CK, Park KW, Lee JH, Lee DH, Wang KC, et al: Scoliosis associated with syringomyelia: analysis of MRI and curve progression. Eur Spine J 16:1629-1635, 2007

\section{Author Contributions}

Conception and design: Couture. Acquisition of data: Rodriguez, Kuhn, Somasundaram. Analysis and interpretation of data: Rodriguez, Kuhn. Drafting the article: Rodriguez, Kuhn, Somasundaram. Critically revising the article: Couture, Rodriguez, Kuhn. Reviewed submitted version of manuscript: all authors. Statistical analysis: Kuhn. Administrative/technical/material support: all authors. Study supervision: Couture, Rodriguez.

\section{Correspondence}

Daniel E. Couture, Department of Neurosurgery, Wake Forest Baptist Medical Center, Medical Center Blvd., Winston-Salem, NC 27157. email: dcouture@wakehealth.edu. 